\title{
DELAYED HYDRIDE CRACKING IN ZIRCALOY FUEL CLADDING - AN IAEA COORDINATED RESEARCH PROGRAMME
}

\author{
C. COLEMAN ${ }^{*}$, V. GRIGORIEV ${ }^{2}$, V. INOZEMTSEV ${ }^{3}$, V. MARKELOV ${ }^{4}$, M. ROTH ${ }^{5}$, V. MAKAREVICIUS ${ }^{6}$, Y. S. KIM ${ }^{7}$, \\ KANWAR LIAGAT ALI ${ }^{8}$, J.K. CHAKRAVARTTY ${ }^{9}$, R. MIZRAHI ${ }^{10}$ and R. LALGUDI ${ }^{11}$ \\ ${ }^{1}$ AECL, Chalk River Laboratories, Chalk River, Ontario, Canada, K0J 1 J0 \\ ${ }^{2}$ Studsvik Nuclear AB, 61182 Nykoeping, Sweden \\ ${ }^{3}$ IAEA, Nuclear Fuel Cycle and Materials Section, Division of Nuclear Fuel Cycle and Waste Technology, Department of Nuclear \\ Energy, Wagramer Strasse 5, A-1400 Vienna, Austria \\ ${ }^{4}$ VNIINM, A. A. Bochvar All Russia Research Institute of Inorganic Materials, P.O. Box 369, 123060 Moscow, Russian Federation \\ ${ }^{5}$ Institute for Nuclear Research, P.O.Box 78, Piteşti, Str. Campului no. 1, Mioveni, Arges, Romania \\ ${ }^{6}$ Lithuanian Energy Institute, Breslaujos 3, 44403 Kaunas, Lithuania \\ ${ }^{7}$ Korea Atomic Energy Research Institute, 150 Dukjin-dong, Yuseong, Daejeon 305-353, Republic of Korea \\ ${ }^{8}$ Pakistan Institute of Nuclear Science and Technology, P.O. Nilore, Islamabad, Pakistan \\ ${ }^{9}$ Department of Atomic Energy, Bhabha Atomic Research Centre, Materials Science Division, Mumbai-400 085, India \\ ${ }^{10}$ Comision Nacional de Energia Atomica, Av. Gral. Paz 1499, B1650KNA San Martin, Pcia. de Buenos Aires, Argentina \\ ${ }^{11}$ Instituto de Pesquisas Energéticas e Nucleares \\ Av. Prof. Lineu Prestes 2242, Cidade Universitària 05508-000, C.P. 11049, Sao Paulo S.P., Brazil \\ *Corresponding author. E-mail : colemanc@aecl.ca
}

Received January 7, 2009

Accepted for Publication January 22, 2009

The rate of delayed hydride cracking (DHC), V, has been measured in cold-worked and stress-relieved Zircaloy-4 fuel cladding using the Pin-Loading Tension technique. At $250{ }^{\circ} \mathrm{C}$ the mean value of $\mathrm{V}$ from 69 specimens was $3.3( \pm 0.8) \times 10^{-8} \mathrm{~m} / \mathrm{s}$ while the temperature dependence up to $275^{\circ} \mathrm{C}$ was described by Aexp(-Q/RT), where Q is $48.3 \mathrm{~kJ} / \mathrm{mol}$. No cracking or cracking at very low rates was observed at higher temperatures. The fracture surface consisted of flat fracture with no striations. The results are compared with previous results on fuel cladding and pressure tubes.

KEYWORDS : Zircaloy-4, Delayed Hydride Cracking (DHC), Temperature Dependence

\section{INTRODUCTION}

A mechanism of flaw extension called Delayed Hydride Cracking (DHC) has been implicated in the failure of $\mathrm{Zr}$ $2.5 \mathrm{Nb}$ pressure tubes [1] and may contribute to long axial splits observed in some LWR fuel cladding [2,3]. The requirements for DHC are for sufficient time for enough hydrogen to accumulate to form, grow and crack hydrides at a stressed flaw tip. These requirements may be met in fuel cladding during reactor operation and during storage. Hydrogen is picked up during corrosion and only needs to exceed a concentration of $115 \mathrm{ppm}$ to be present at $300{ }^{\circ} \mathrm{C}$ or $185 \mathrm{ppm}$ to be present at $350{ }^{\circ} \mathrm{C}$; fretting or interactions with the fuel may generate flaws; internal gas pressures or fuel expansion may impose tensile hoop stresses. The rate of $\mathrm{DHC}, \mathrm{V}$, is characterized by being almost independent of $K_{I}$ once a threshold value, $K_{I H}$, is exceeded and increases rapidly with increase in temperature; an upper temperature limit has been observed in $\mathrm{Zr}-2.5 \mathrm{Nb}$ pressure tube material above which DHC is very difficult.

The physical conditions for DHC in unirradiated Zircaloy fuel cladding are being studied in an interlaboratory comparison organized by the IAEA. A similar exercise was successfully concluded on $\mathrm{Zr}-2.5 \mathrm{Nb}$ pressure tube materials [4]; by using a standard method of testing with compact toughness specimens, uniform sets of data were attained in laboratories in ten countries. The same principles are being applied for the testing of Zircaloy-4 fuel cladding in nine countries. Several methods are available for testing such thin-walled, small diameter material: a centre-cracked half-tube loaded in tension [5] a centre-cracked length of tube loaded by a wedge and mandrel (SPLIT test) [6] and the Pin-Loading Tension (PLT) technique [7]. The last method was chosen for this 

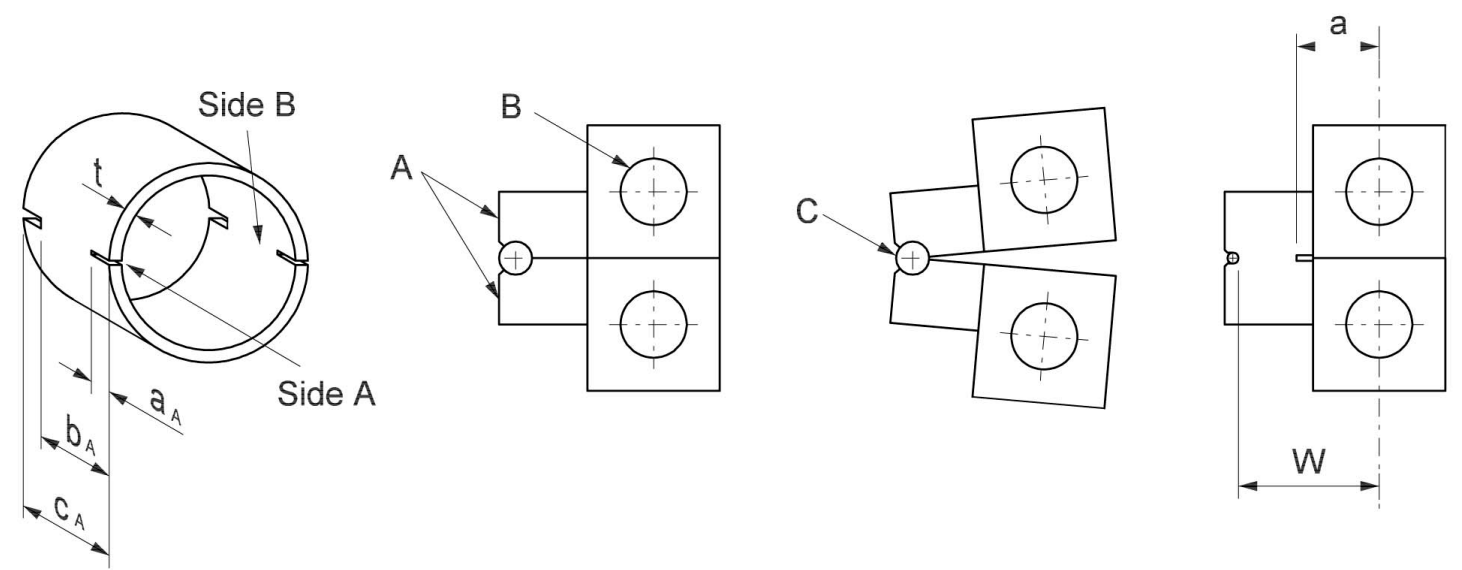

Fig. 1. Schematic Diagram of the PLT Specimen, Fixture, and Specimen-Fixture Assembly

programme because its loading was similar to that in a compact toughness specimen and was considered to be most amenable for technology transfer. The objectives of this programme were to evaluate the efficacy of the technology transfer and measure temperature dependence of the rate of DHC on a single material.

\section{EXPERIMENTAL}

The test programme had two phases. In the first phase, Studsvik prepared test fixtures and specimens from a batch of Zircaloy-4 cladding in the stress relief annealed (SRA) condition and each laboratory tested their allocation of specimens in a prescribed manner at a single temperature, $250{ }^{\circ} \mathrm{C}$. Using this experience, during the second phase, each laboratory prepared their own specimens out of segments of similar tubing and tested them at two assigned temperatures.

The material used for the experiments was standard Zircaloy-4 that had been cold-worked $80 \%$ and stressrelieved at $480{ }^{\circ} \mathrm{C}$ for $3.5 \mathrm{~h}$. The composition was $\mathrm{Sn}$ 1.26 wt.\%, Fe 0.22 wt.\%, Cr 0.10 wt.\%, O 1220 ppm, Si $100 \mathrm{ppm}$ and C $120 \mathrm{ppm}$. The tube dimensions were 9.52 $\mathrm{mm}$ outside diameter with wall thickness of $0.57 \mathrm{~mm}$. The grains were elongated axially, with 5 to $10 \%$ recrystallized grains; the basal plane normals were concentrated about $30^{\circ}$ from the radial direction with texture factors in the radial, transverse and axial directions of $0.66,0.30$, and 0.04 , respectively. The strength of the material was measured with ring tensile tests as a function of temperature, $\mathrm{T}^{\circ} \mathrm{C}$. Between $200{ }^{\circ} \mathrm{C}$ and $320{ }^{\circ} \mathrm{C}$ the UTS varied as $(683-0.71 \mathrm{~T}) \mathrm{MPa}$. Depositing a layer of hydride on the surfaces electrolytically and diffusing the hydrogen in to the metal by annealing at $410{ }^{\circ} \mathrm{C}$ for $24 \mathrm{~h}$ added hydrogen for a total concentration of about $200 \mathrm{ppm}$. The specimen and test fixture are shown in Fig. 1. The $13 \mathrm{~mm}$ long specimen $\left(\mathrm{c}_{\mathrm{A}}\right)$ contained diametrally opposite axial notches at both edges with those at one end being sharpened by fatigue at room temperature for a starting length of $a_{A}$; the notch at the other end provided an effective specimen length of $b_{A}$. The fatigue pre-cracking was done at 5-10 $\mathrm{Hz}$ with starting cycling loads of $200 \mathrm{~N}$ to $50 \mathrm{~N}$. The maximum load was gradually reduced to $100 \mathrm{~N}$ as the crack progressed. The final load was chosen to be lower than the starting load for the DHC test, $160 \mathrm{~N}$, so the plastic zone at the crack tip from fatigue did not interfere with DHC. About 20000 cycles were required to produce a suitable starting crack.

The PLT-fixture consisted of two halves, which, when placed together, form a cylindrical holder, A. The diameter of the holder allowed it to be inserted into the specimen while maintaining a small gap. The fixture halves were loaded in tension through pins at $\mathbf{B}$ and rotated about a pin $\mathbf{C}$ at the ends of the cylindrical holder providing the similarity to the loading of a compact toughness specimen, but on two cracks. During a test, the specimen was heated to and held at a temperature 50 to $75{ }^{\circ} \mathrm{C}$ above the test temperature, cooled with no undercooling to the test temperature, then loaded to a $K_{I}$ of about $15 \mathrm{MPa} \sqrt{m}_{\mathrm{m}}$ once the temperature was constant. The value of $\mathrm{K}_{\mathrm{I}}$ was calculated from Equation (1):

$$
\mathrm{K}_{\mathrm{I}}=[\mathrm{P} /(2 \mathrm{t} \sqrt{ } \mathrm{W})] f(\mathrm{a} / \mathrm{W})
$$

where $\mathrm{P}=\operatorname{load}(\mathrm{N})$;

$\mathrm{t}=$ wall thickness of the cladding (m);

$\mathrm{W}=$ effective width of specimen (m); see Fig. 1; $\mathrm{a}=$ effective crack length (m); see Fig. 1 .

$f(\mathrm{a} / \mathrm{W})=$ geometry correction factor.

Cracking was detected either by potential drop or by 


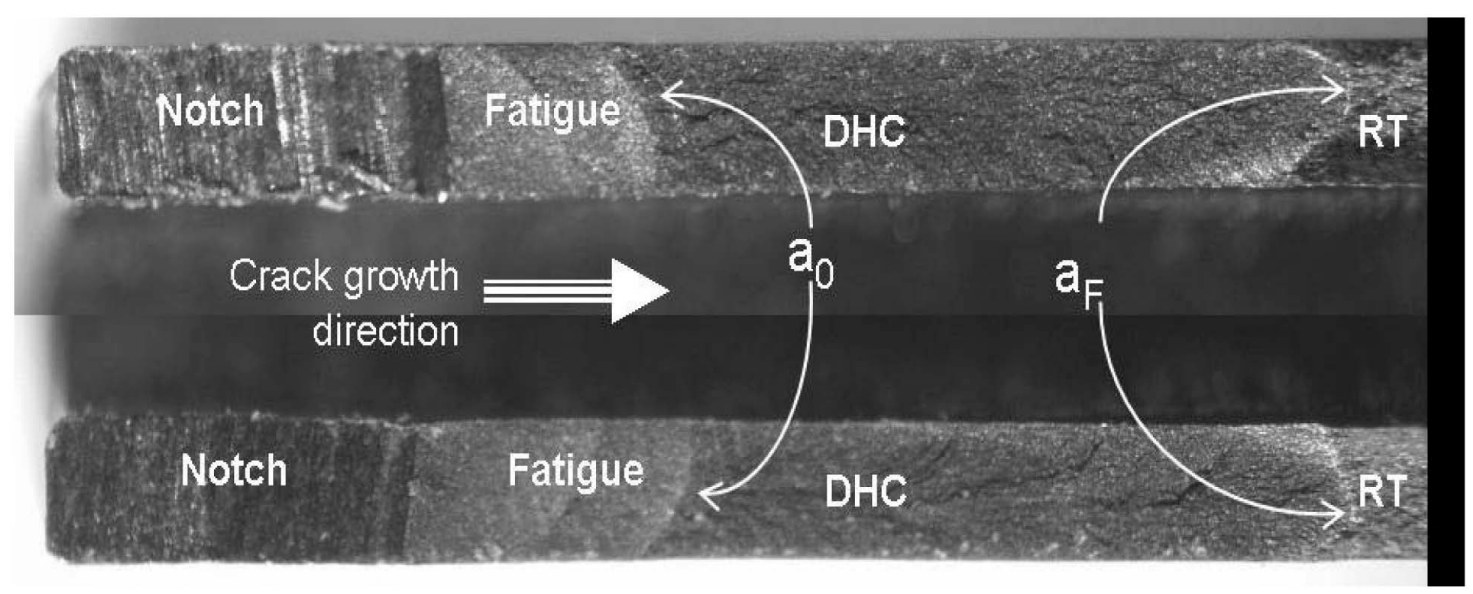

Fig. 2. View of the Fracture Surfaces of Unirradiated SRA Zircaloy-4 Specimen (205 ppm of Hydrogen). The Top and Bottom Edges are the Outside Surfaces of the Cladding. The Initial $\left(a_{0}\right)$ and the Final $\left(a_{F}\right)$ Length of the DHC Crack are Indicated as well as the Areas of Notch, Fatigue Pre-Cracking, DHC Crack Propagation and Room Temperature Fracture after the DHC Test (RT)

displacement (crack opening). Once the cracks had extended about $2 \mathrm{~mm}$, the load was removed and the specimen cooled to room temperature and broken open. Often an incubation period, $t_{i}$, was required before DHC started; cracking time, $t_{\mathrm{T}}$, was taken as (time under load $\mathrm{t}_{\mathrm{i}}$ ). Crack growth by DHC, $\mathrm{a}_{\mathrm{F}}-\mathrm{a}_{0}$ (Fig. 2), was estimated on each crack from the average of nine equi-spaced measurements or by measuring the area of fracture due to DHC and dividing by the tube wall thickness; the value for the specimen, as, was the average of the values of the two cracks. Crack velocity, V, in the axial direction of the cladding was $a_{s} / t_{\text {T. }}$ A Scanning Electron Microscope (SEM) was used to examine the fracture surfaces of some specimens.

\section{RESULTS}

A typical fracture surface is depicted in Fig. 2 where the various stages of the test are visible as bands of different colour and roughness. Both fatigue cracks are characterized by a gently curved crack front, being longer on the inside surfaces because $\mathrm{K}_{\mathrm{I}}$ is slightly larger than on the outside surface because of bending. The DHC fracture surface does not contain similar inside-outside characteristics because $\mathrm{V}$ is insensitive to $\mathrm{K}_{\mathrm{I}}$ but has a region where the crack is held up at each specimen surface corresponding to a less constrained stress state.

The main fractographic feature is flat fracture associated with cleavage of hydride, Fig. 3. Striations, often associated with $\mathrm{DHC}$ in $\mathrm{Zr}-2.5 \mathrm{Nb}$ pressure tube material, were not observed.

The values of $\mathrm{V}$ at $250{ }^{\circ} \mathrm{C}$ in Zircaloy- 4 obtained by each laboratory are summarized in Table 1 . The range of the mean value of each set of data was from 2.03 to

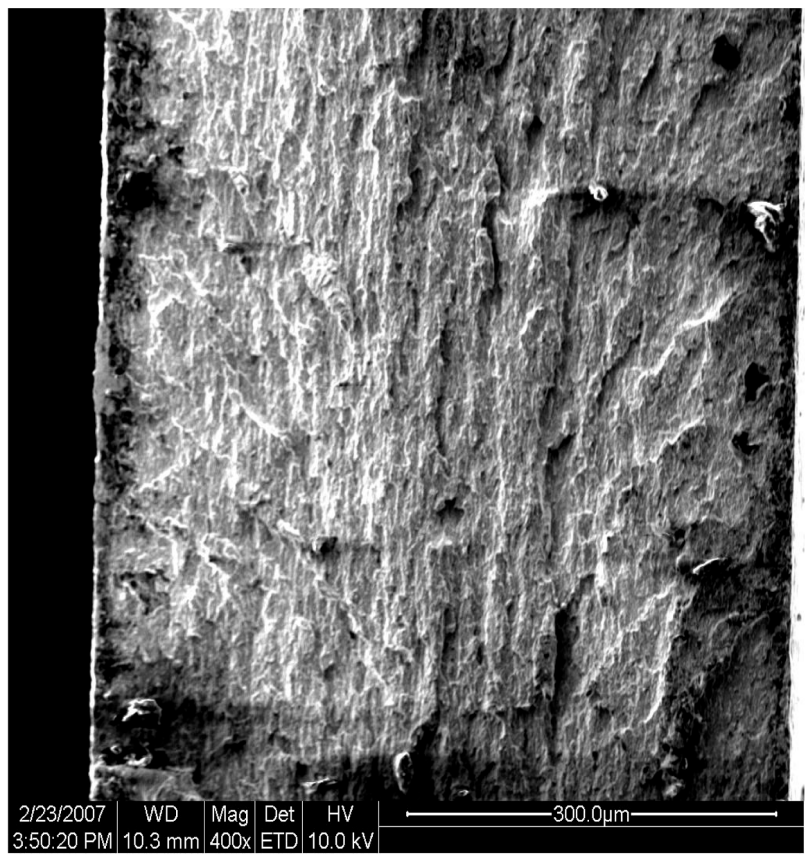

Fig. 3. Fracture Surface of Zircaloy- 4 after DHC at $250^{\circ} \mathrm{C}$;

Crack Growing from Bottom of Photograph. Note the Areas of Flat Fracture Corresponding to Broken Hydrides

$3.97 \times 10^{-8} \mathrm{~m} / \mathrm{s}$ while the standard deviation ranged from 0.27 to $0.76 \times 10^{-8} \mathrm{~m} / \mathrm{s}$ although most values were less than $0.5 \times 10^{-8} \mathrm{~m} / \mathrm{s}$. The maximum and minimum values of $\mathrm{V}$ were $4.72 \times 10^{-8} \mathrm{~m} / \mathrm{s}$ and $1.57 \times 10^{-8} \mathrm{~m} / \mathrm{s}$, respectively. The data from all 69 specimens had a mean value of $3.34 \times 10^{-8} \mathrm{~m} / \mathrm{s}$ and a standard deviation of $0.80 \times 10^{-8} \mathrm{~m} / \mathrm{s}$. The distribution of the values of $\mathrm{V}$ is shown in Fig. 4. 
COLEMAN et al., Delayed Hydride Cracking in Zircaloy Fuel Cladding - an IAEA Coordinated Research Programme

Table 1. Summary of Values of Crack Velocity, $\mathrm{V}$, at $250^{\circ} \mathrm{C}$ for SRA Zircaloy-4 Fuel Cladding $\left(x 10^{-8} \mathrm{~m} / \mathrm{s}\right)$ from each Laboratory

\begin{tabular}{lccccccccc}
\hline Laboratory & $\mathrm{A}$ & $\mathrm{B}$ & $\mathrm{C}$ & $\mathrm{D}$ & $\mathrm{E}$ & $\mathrm{F}$ & $\mathrm{G}$ & $\mathrm{H}$ & $\mathrm{I}$ \\
\hline Mean V & 3.45 & 2.34 & 2.91 & 3.61 & 3.56 & 3.81 & 2.03 & 3.97 & 3.67 \\
Standard deviation & 0.48 & 0.39 & 0.45 & 0.76 & 0.36 & 0.7 & 0.27 & 0.34 & 0.32 \\
Number of specimens & 7 & 6 & 4 & 8 & 8 & 8 & 7 & 13 & 8 \\
\hline
\end{tabular}

Table 2. Temperature Dependence of Crack Velocity, V, (x10-8 m/s) for Delayed Hydride Cracking in SRA Zircaloy-4

\begin{tabular}{lllllllll}
\hline Test temperature, ${ }^{\circ} \mathrm{C}$ & 150 & 200 & 227 & 250 & 275 & 283 & 290 & 300 \\
\hline Crack velocity $10^{-8} \mathrm{~m} / \mathrm{s}$ & 0.3 & 0.86 & 2.1 & 3.3 & 6.8 & 4.7 or 0 & 0 & 0.55 or 0 \\
\hline
\end{tabular}

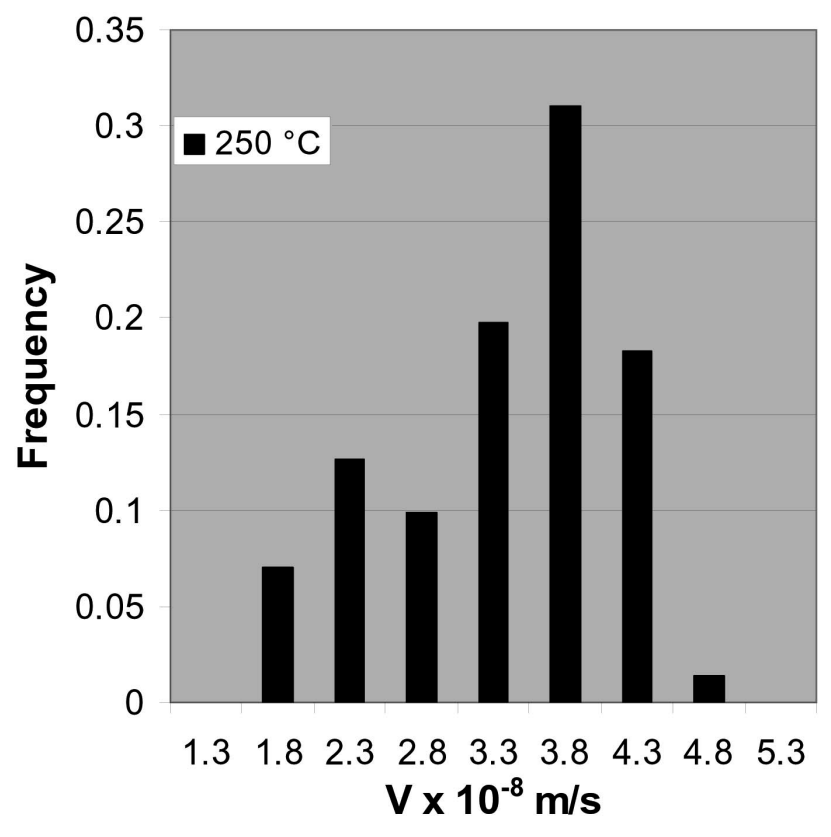

Fig. 4. Distribution of Values of DHC Velocity, V, in SRA Zircaloy-4 Fuel Cladding

In contrast to the well-behaved values of $\mathrm{V}$, the incubation times exhibited a very large variation. The mean value was $3520 \mathrm{~s}$ with a standard deviation of 4230 s, sometimes the cracking started immediately on loading whereas in some specimens $18000 \mathrm{~s}$ were required before the crack started to propagate. Some of this variation was attributable to the sensitivity of the crack detection system but most was probably caused by the variability in the stress state of the fatigue-sharpened crack.

The values of $\mathrm{V}$ at other temperatures are summarized in Table 2. Below $275{ }^{\circ} \mathrm{C}$ the values of crack velocity have a clear and highly correlated $\left(\mathrm{R}^{2}=0.98\right)$ temperature dependence described by Equation (2):

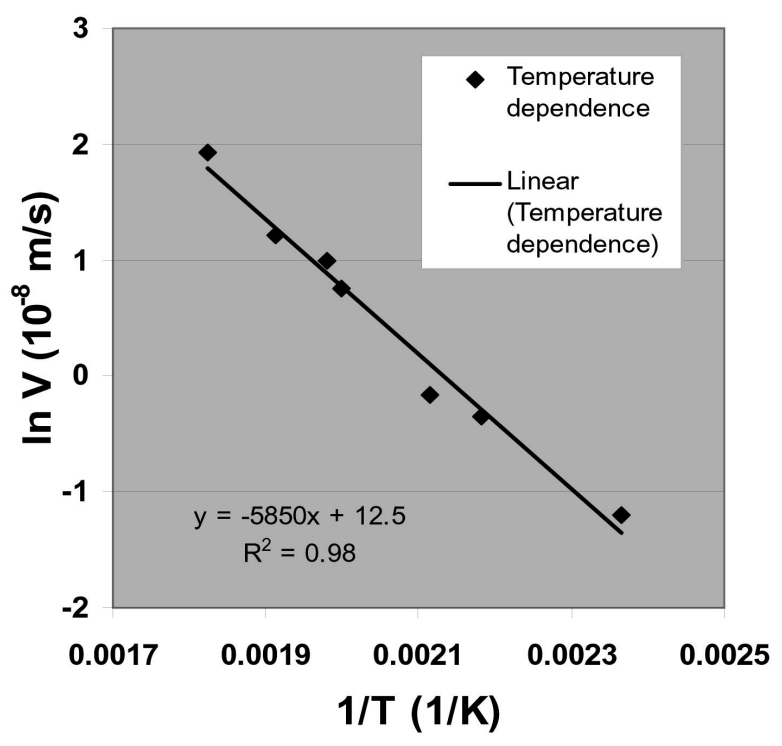

Fig. 5. Temperature Dependence of DHC Velocity, V, in SRA Zircaloy-4 Fuel Cladding

$$
\mathrm{V}=\mathrm{Aexp}(-\mathrm{Q} / \mathrm{RT})
$$

where $\mathrm{Q}=$ activation energy for cracking $(\mathrm{kJ} / \mathrm{mol})$,

$$
\begin{aligned}
& \mathrm{T}=\text { test temperature }(\mathrm{K}), \\
& \mathrm{R}=\text { gas constant }(\mathrm{J} / \mathrm{K} . \mathrm{mol}) \\
& \mathrm{A}=\text { constant }
\end{aligned}
$$

and depicted in Fig. 5. Q has a value of $48.3 \mathrm{~kJ} / \mathrm{mol}$. At temperatures above $275^{\circ} \mathrm{C}$ the rates declined with limited or no cracking observed at $283{ }^{\circ} \mathrm{C}$ and above, even when $\mathrm{K}_{\mathrm{I}}$ was increased to about $18 \mathrm{MPa} \sqrt{\mathrm{m}}$.

\section{DISCUSSION}

The results of these tests confirm that SRA Zircaloy 
fuel cladding can crack by DHC. A consistent set of values was obtained in each laboratory indicating that the testing methodology had been accurately transferred.

The values of $\mathrm{V}$ compare favourably with those from pressure tubes made from Zircaloy $[8,9]$ and fuel cladding $[5,7]$, Fig. 6. The temperature dependencies characterized by Q were $69.5 \mathrm{~kJ} / \mathrm{mol}$ and $55.5 \mathrm{~kJ} / \mathrm{mol}$ for pressure tube materials $[8,9]$. The discrepancies in both $\mathrm{V}$ and $\mathrm{Q}$ can be attributed to:

- differences in temperature and loading histories, which can contribute large variations in $\mathrm{V}$,

- small numbers of samples, which provides low confidence in the statistical evaluation of Q, and

- differences in microstructure, including texture, and strength.

The temperature dependence of $\mathrm{DHC}$ is dominated by the diffusivity, D, and solubility limit, $\mathrm{C}$, of hydrogen in zirconium and to a lesser extent by the strength. To provide a guideline and to compare the behaviour of different materials in different conditions a useful normalization is that of Oh et al. [10]. Fig. 7 illustrates the normalization using UTS as the strength characterization (because that is the only strength quantity measured in ring tensile tests on fuel cladding in the current study). The values of $D$ and $\mathrm{C}$ used for this exercise are derived from Sawatzky (Zircaloy [11] and Zr-2.5Nb [12]) and Kearns [13] while the values of UTS are mostly provided in the papers on DHC. The current results fit into the broad band of data on several different materials in different metallurgical conditions, including irradiation [4, 7-9, 14] indicating that the DHC behaviour of fuel cladding is as expected from the experience with pressure tube materials.

The decline of DHC at high temperatures has been observed in both $\mathrm{Zr}-2.5 \mathrm{Nb}$ [15-17] and Zircaloy [14].

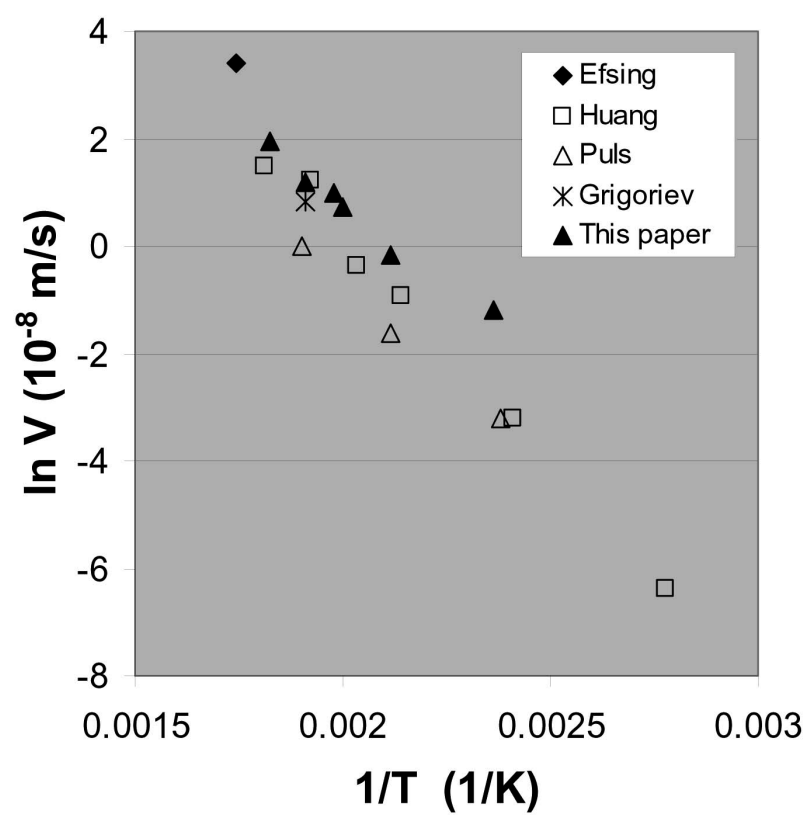

Fig. 6. The Temperature Dependence of V in Zircaloy

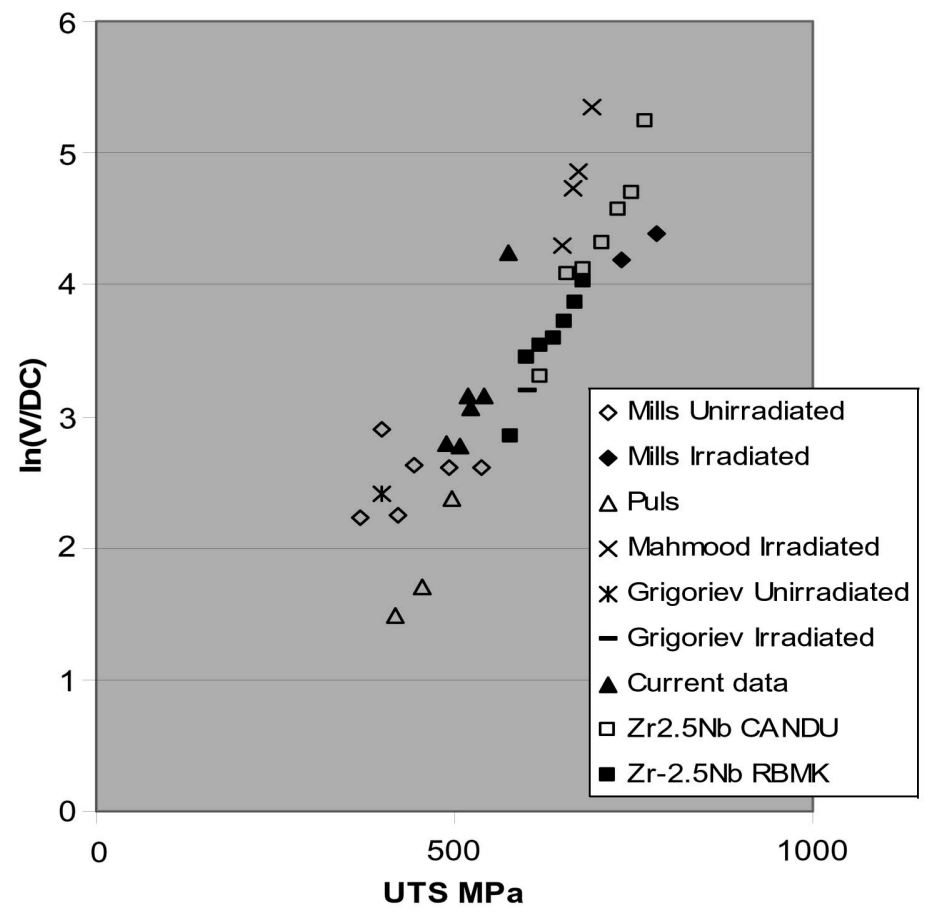

Fig. 7. Normalization of DHC Velocity, V, with the Diffusivity, D, and Solubility Limit for Dissolution, C 


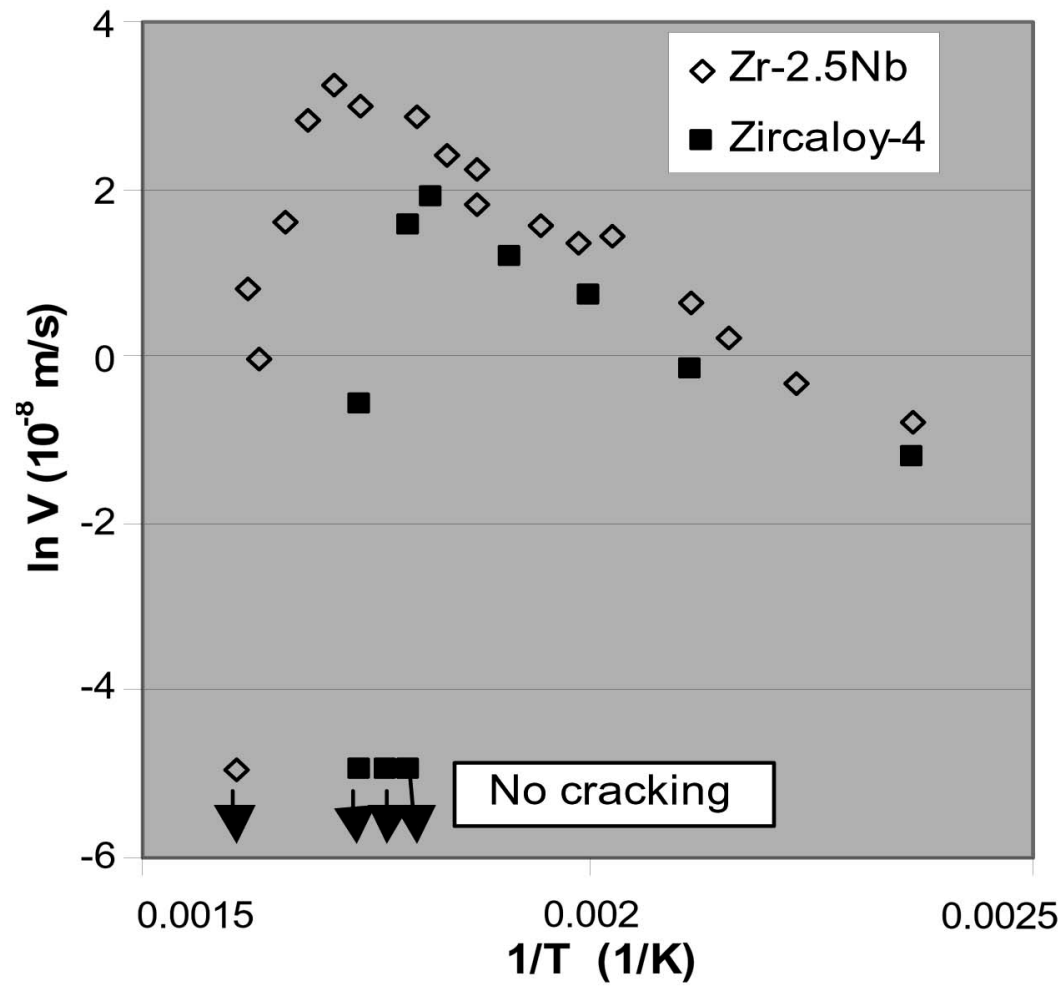

Fig. 8. High Temperature Crack Velocity Results for Cold-Worked Zr-2.5Nb [16] and SRA Zircaloy-4 [this Paper]

Fig. 8 is a direct comparison of the behaviour of coldworked $\mathrm{Zr}-2.5 \mathrm{Nb}$ pressure tube material [16] and SRA Zircaloy-4 fuel cladding. In $\mathrm{Zr}-2.5 \mathrm{Nb}$ the crack velocity starts to deviate from the Arrhenius correlation at about $310^{\circ} \mathrm{C}$ with no cracking detected at $350{ }^{\circ} \mathrm{C}$ while in the current Zircaloy-4 the initial deviation is at about $275^{\circ} \mathrm{C}$ with little or no cracking at $300^{\circ} \mathrm{C}$.

The rate of DHC can be suppressed when:

- the hydrogen concentration is insufficient for hydrides to form at the crack tip. The current specimens contain $200 \mathrm{ppm}$ hydrogen, which is sufficient for hydrides to be present at temperatures up to $360{ }^{\circ} \mathrm{C}$, even on cooling to the test temperature. Thus the observed reduced rate of cracking is not caused by lack of hydride.

- the temperature history prevents hydrides from forming at the crack tip. Heating to the test temperatures may cause this situation, even if hydrides are present in the metal matrix [18]. In the current tests the test temperature was always attained by cooling from at least $50^{\circ} \mathrm{C}$ above the test temperature, with no undercooling, so this effect is not the cause of the reduced velocity.

- $\mathrm{K}_{\mathrm{IH}}$ becomes greater than the applied $\mathrm{K}_{\mathrm{I}}$. In $\mathrm{Zr}-2.5 \mathrm{Nb}$, $\mathrm{K}_{\mathrm{IH}}$ has little temperature dependence at temperatures below $300{ }^{\circ} \mathrm{C}$ but at higher temperatures it increases rapidly [17]. Zircaloy-4 likely behaves in a similar manner implying that $\mathrm{K}_{\mathrm{IH}}$ increases to values greater than about
$15 \mathrm{MPa} \sqrt{\mathrm{m}}$ above $280^{\circ} \mathrm{C}$. A corollary to this behaviour is that $\mathrm{V}$ and the crack suppression temperature will appear to depend on $\mathrm{K}_{\mathrm{I}}$. Close to the critical temperature, a small amount of evidence supports this conclusion. In $\mathrm{Zr}-2.5 \mathrm{Nb}$ the range of the suppression temperature increased from $280-313{ }^{\circ} \mathrm{C}$ to $328-359{ }^{\circ} \mathrm{C}$ when $\mathrm{K}_{\mathrm{I}}$ was increase from $13 \mathrm{MPa} \sqrt{\mathrm{m}}$ to $17 \mathrm{MPa} \sqrt{\mathrm{m}}$ [15]. In the current study at $283{ }^{\circ} \mathrm{C}$ in one specimen no cracking was detected after $9000 \mathrm{~s}$ at a $\mathrm{K}_{\mathrm{I}}$ of $15 \mathrm{MPa} \sqrt{\mathrm{m}}$ but once $\mathrm{K}_{\mathrm{I}}$ was increased by about $7 \%$ the crack progressed, but at a much reduced rate based on expectations from an extrapolation of Equation (2).

In this study, as in others on Zircaloy $[5,7,8]$ the fractographic features called striations were absent. These observations are in marked contrast to the fractography of $\mathrm{Zr}-2.5 \mathrm{Nb}$ where striations are easily observed. Striations are bands across most of the width of a specimen, perpendicular to the crack growth direction, consisting of regions of ductile fracture bounding cleavage of hydride. They tend to remain a constant width and coplanar as the crack extends. In Zircaloy, the hydrides fracture on different planes along the crack front with ductile fracture between the brittle plates. The size of the brittle areas is variable so bands of consistent width are not formed. Microstructural features contributing to the difference in behaviour of the two materials are probably the finer scale 
of the grains and presence of a $\beta$-phase in $\mathrm{Zr}-2.5 \mathrm{Nb}$. The lack of striations with DHC in Zircaloy suggests that they are not a unique characteristic of DHC.

The maximum value of $\mathrm{V}$ in this study was $6.8 \times 10^{-8}$ $\mathrm{m} / \mathrm{s}$ at $275^{\circ} \mathrm{C}$, which is four to ten times lower than the rates estimated from splits in BWR's [3]. The current results are not suitable for direct application to the behaviour of fuel cladding because the material is unirradiated. The added strength generated by irradiation has two consequences: the crack velocity is increased by a factor between ten to fifty [7, 8, 19] easily agreeing with the rates observed in-reactor, and the high temperature decline in velocity is postponed to higher temperatures [17]. Other differences between cladding on an operating fuel element and these laboratory experiments include temperature gradients, which can affect crack velocity and response to temperature history [20]. Nevertheless, these data provide a basis from which to build a data set for future reference.

\section{CONCLUSIONS}

The PLT technique for measuring DHC has been transferred to eight IAEA member states. Tests on CWSR Zircaloy-4 fuel cladding have provided reliable values of crack velocity that had an Arrhenius-type temperature dependence up to $275^{\circ} \mathrm{C}$ followed by a drop off in rate at higher temperatures. No striations were observed suggesting that they are not a fundamental feature of DHC. The current results were compatible with those obtained in the first part of this programme on $\mathrm{Zr}-2.5 \mathrm{Nb}$ pressure tube material, once the differences in microstructure and strength were taken into consideration. This agreement provides confidence in the PLT method for estimating DHC properties in fuel cladding.

\section{ACKNOWLEDGMENTS}

We are grateful for the contributions from B. Johansson (Studsvik), V. Fierro (CITEFA), A. Grybenas (LEI), M. Resta Levi (AECL), A. Kundu (BARC), and A.A. Khan (PINS).

\section{REFERENCES}

[ 1 ] E. C. W. Perryman, "Pickering Pressure Tube Cracking Experience", Nuclear Energy, 17, 95-105, (1978).

[2] D. Schrire, B. Grapengiesser, L. Hallstadius, L. Lundholm, G. Lysell, G. Frenning, G. Rönnberg, and A. Jonsson, "Secondary Defect Behaviour in ABB BWR Fuel", Proc. International Topical Meeting on Light Water Reactor Fuel Performance, ANS, West Palm Beach, 398-409, (1994).

[3 ] K. Edsinger, "A Review of Fuel Degradation in BWRs", Proc. International Topical Meeting on Light Water Reactor Fuel Performance, ANS, Park City, USA, 162-179, (2000).

[4] C. E. Coleman and V. V. Inozemstev, "Measurement of Rates of Delayed Hydride Cracking (DHC) in $\mathrm{Zr}-2.5 \mathrm{Nb}-$
An IAEA Coordinated Research Project", J. ASTM International, 5 (2), Paper ID: 101091, (2008).

[5] P. Efsing and K. Pettersson, "The Influence of Temperature and Yield Strength on Delayed Hydride Cracking in Hydrided Zircaloy-2", Zirconium in the Nuclear Industry: Eleventh International Symposium", ASTM STP 1295, 394-404, (1996).

[6] K. Edsinger, J. H. Davies and R. B. Adamson, "Degraded Fuel Cladding Fractography and Fracture Behaviour", Zirconium in the Nuclear Industry: Twelfth International Symposium”, ASTM STP 1354, 316-339, (2000).

[7] V. Grigoriev and R. Jakobsson, "Delayed Hydrogen Cracking velocity and J-Integral Measurements on Irradiated BWR Cladding", Zirconium in the Nuclear Industry: Fourteenth International Symposium", ASTM STP 1467, 711-728, (2006).

[ 8 ] F. H. Huang and W. J. Mills, "Delayed Hydride Cracking Behavior for Zircaloy-2 Tubing", Metallurgical Transactions, 22A, 2049-2060, (1991).

[9] M. P. Puls, L. A. Simpson and R. Dutton, "Hydride-induced Crack Growth in Zirconium Alloys", AECL Report, AECL7392, (1982).

[10] J. Y. Oh, I. S. Kim and Y. S. Kim, "A Normalization Method for Relationship between Yield Stress and Delayed Hydride Cracking Velocity in Zr-2.5Nb Alloy", J. Nuclear Science and Technology, 37, 595-600, (2000).

[11] A. Sawatzky, "The Diffusivity and Solubility of Hydrogen in the Alpha-phase of Zircaloy", J. Nuclear Materials, 2, 62-68, (1960).

[12] A. Sawatzky, G. A. Ledoux, R. L. Tough, C. D. Cann, "Hydrogen Diffusion in Zirconium-Niobium Alloys, Proc. International Symposium on Metal-Hydrogen Systems, Pergamon Press, 109-120, (1981).

[13] J. J. Kearns, "Terminal solubility and Partitioning of hydrogen in the Alpha Phase of Zirconium, Zircaloy-2 and Zircaloy-4, J. Nuclear Materials, 22, 292-303, (1967).

[14] S. T. Mahmood, D .M. Farkas, R. B. Adamson and Y. Etoh, "Post-Irradiation Characterization of Ultra-High-Fluence Zircaloy-2 Plate," Zirconium in the Nuclear Industry: Twelfth International Symposium, ASTM STP 1354, 139$169,(2000)$.

[15] R. R. Smith and R. L.Eadie, "High Temperature Limit for Delayed Hydride Cracking", Scripta Metallurgica, 22, 833-836, (1988).

[16] S. Sagat and M. P. Puls, "Temperature Limit for Delayed Hydride Cracking in Zr-2.Nb Alloys," 17 th Inter. Conf. Structural Mechanics in Reactor Technology, Paper G06-4, (2003).

[17] M. Resta Levi and M. P. Puls, "DHC Behaviour of Irradiated $\mathrm{Zr}-2.5 \mathrm{Nb}$ Pressure Tubes up to $365^{\circ} \mathrm{C}$," $18^{\text {th }}$ Inter. Conf. Structural Mechanics in Reactor Technology, Paper G103, (2005).

[18] J. F. R. Ambler, "Effect of Direction of Approach to Temperature on the Delayed Hydride Cracking Behaviour of Cold-worked Zr-2.5Nb," Zirconium in the Nuclear Industry: Sixth International Symposium, ASTM STP 824, 653-674, (1984).

[19] S. Sagat, C. E. Coleman, M. Griffiths and B. J. S. Wilkins, "Effect of Fluence and Irradiation Temperature on Delayed Hydride Cracking in $\mathrm{Zr}-2.5 \mathrm{Nb}$," Zirconium in the Nuclear Industry: Tenth International Symposium, ASTM STP 
COLEMAN et al., Delayed Hydride Cracking in Zircaloy Fuel Cladding - an IAEA Coordinated Research Programme

1245, 35-61, (1994).

[20] S. Sagat, C. K. Chow, M. P. Puls and C. E. Coleman,
"Delayed Hydride Cracking in a Temperature Gradient," J. Nuclear Materials, 279, 107-117, (2000). 